\title{
Lacticodeshydrogénase (LDH) and Ferrétinémia, Biomarkers of Coronavirus disease (COVID-19)
}

Nawal Brikci Nigassa ${ }^{1}$ and Mustapha Haddouche ${ }^{2 *}$

${ }^{I}$ Tlemcen University Hospital, Biochemistry service, Faculty of Medicine Department of Medicine.

${ }^{2}$ Tlemcen University, Faculty of Medicine, Department of Pharmacy.

\section{"Correspondence author \\ Dr. Mustapha Haddouche Assoc Professor}

Laboratory of Applied Molecular Biology and Immunology Tlemcen Abou-Bekr Belkaïd University

Algeria

Submitted : 15 May 2020 ; Published : 15 June 2020

\begin{abstract}
Background
Coronavirus disease (COVID-19) is caused by SARS-COV2 and represents the causative agent of a potentially fatal disease that is of great global public health concern [1-2]. Its involves humans as well as animals and may cause serious damage to the respiratory tract, including the lung: coronavirus disease (COVID-19). This pathogenic virus has been identified in swabs performed on the throat and nose of patients who suffer from or are suspected of the disease [1]. Based on the large number of infected people that were exposed to the wet animal market in Wuhan City, China, it is suggested that this is likely the zoonotic origin of COVID-19 [2].
\end{abstract}

Keywords: Covi-19, Ferriinemia, LDH.

\section{Introduction}

The virus that causes COV-19 is spread mainly by droplets produced when infected person Coughs sneezes or expires. This droplet is too heavy to stay in the air and fall quickly to the ground or any nearby surface. People with Covi-19 have severe respiratory failure, or lack of oxygen, which involves an imbalanced cytoplasmic and mitochondrial metabolism (Effect Warburg), important activity of enzyme lacicideshydrogénase ( $\mathrm{LDH})$, production of acid lactic, muscular weakness on the one hand Ferritin is a protein that fixes iron (Fe) contributes to the oxygenation of blood and organs. The main role of iron is to transport and store the oxygen contained in the blood to the organs and muscles to human body. It is essential for the formation of hemoglobin protein found in red cells.

When COVI-19 infect the upper and lower respiratory tract it can cause mild or highly acute respiratory syndrome with consequent release of pro-inflammatory cytokines, including interleukin (IL)-1 $\beta$ and IL-6. [3-7]. In this study, we attempted to evaluate the concentration of the enzyme lacicideshydrogénase, Ferriinemia and iron to investigate the anomalies affecting the anaerobic metabolism. In this respect, a retrospective case-control study conducted at the Tlemcen university hospital, biochemistry service (Algeria).

\section{Materials and Methods}

Twenty patients with Covi-19 and Twenty sex-matched control were recruited for a retrospective case-control study at the Tlemcen university hospital, biochemistry service (Algeria). Characteristics of Patients Covi-19 and Control (Gender (M/F) $6 / 14 ; 9 / 11)$

Age (year) Control (48.4 \pm 4.37$)$; Patients Covi-19 (55.68 \pm 3.68).

The circulating levels of Ferriinemia, LDH, Fer and CRP were evaluated in 20 patients with Covi-19 and 20 controls. The concentrations of studied parameters were measurement by Automated Biochemistry Analysis ADVIA. 1800. Siemens.

The circulating levels of Ferriinemia, LDH, Fer and CRP were evaluated in 20 patients with Covi-19 and 20 controls. The concentrations of studied parameters were measurement by Automated Biochemistry Analysis ADVIA. 1800. Siemens.

\section{Results}

In this study, the circulating levels of LDH, Ferritinemia, Fer and CRP were evaluated in 20 patients with Covi-19 
and 20 controls. Characteristics of Patients Covi-19 and Control are presented in Table1. The biomarkers are shown in Table2. The serum levels of Fer (Iron), Ferritinemia and LDH are show in Figures 1, 2 and 3 respectively. We note that correlation coefficient between the different biomarkers varies proportionally. (Table3.)

\begin{tabular}{|l|l|l|}
\hline Variable & Controls & Patients \\
\hline Gender(M/F) & $6 / 14$ & $9 / 11$ \\
\hline Age(year) & $48.4 \pm 4.37$ & $55.68 \pm 3.68$ \\
\hline
\end{tabular}

Table1: Characteristics of Patients and Control Covi-19

\begin{tabular}{|l|l|l|}
\hline Variable & Controls & Patients \\
\hline Ferritinémia $(\mathrm{ng} / \mathrm{ml})$ & $72.35 \pm 12.02$ & $896.79 \pm 97.70$ \\
\hline Fer $(\mu \mathrm{g} / \mathrm{dl})$ & $85.15 \pm 5.90$ & $20.42 \pm 1.54$ \\
\hline $\mathrm{LDH}(\mathrm{u} / \mathrm{l})$ & $184.3 \pm 9.72$ & $366.32 \pm 33.94$ \\
\hline CRP $(\mathrm{mg} / \mathrm{l})$ & $4.03 \pm 0.30$ & $67.54 \pm 8.08$ \\
\hline
\end{tabular}

Table2: Levels of biomarkers in Covi-19 and Controls

\begin{tabular}{|l|l|l|}
\hline Variable & Pearson & Spearman \\
\hline LDH / Fer & -0.622 & -0.734 \\
\hline LDH/ Ferritinemia & +0.742 & +0.807 \\
\hline LDH/ CRP & +0.679 & +0.711 \\
\hline Fer / Ferritinemia & -0.725 & -0.808 \\
\hline CRP/ Ferritinemia & +0.697 & +0.787 \\
\hline Fer/CRP & -0.655 & -0.8011 \\
\hline
\end{tabular}

Table3: Correlation Coefficient of biomarkers with Covi-19

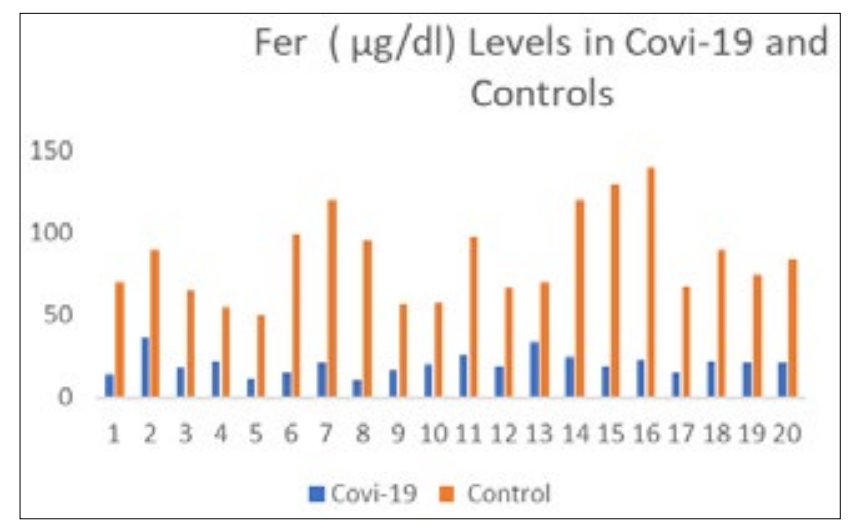

Figure 1: Fer Levels in Covi-19 and Controls. The variables are presented as mean \pm standard error. $P>0.005$.

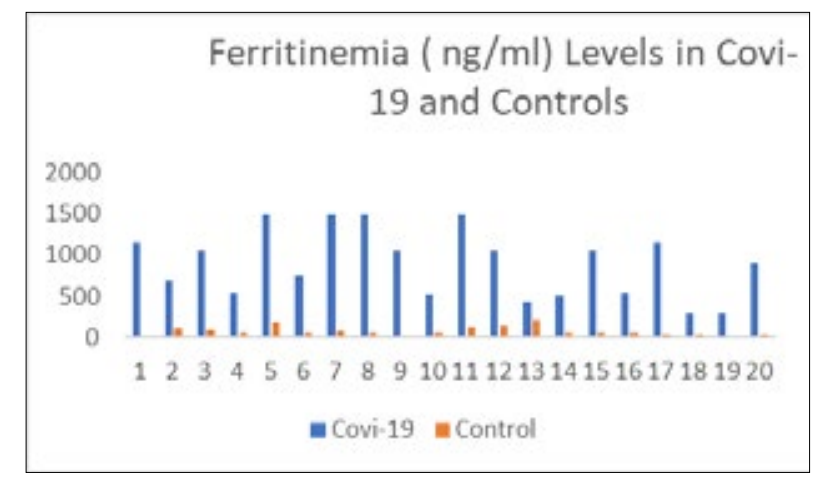

Figure 2: Ferritinemia Levels in Covi-19 and Controls. The variables are presented as mean \pm standard error. $P>0.005$.

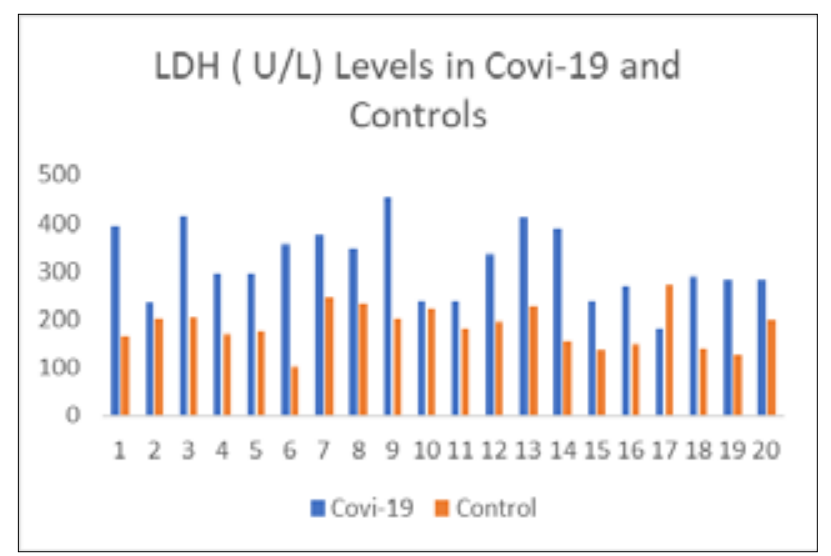

Figure 3: LDH Levels in Covi-19 and Controls. The variables are presented as mean \pm standard error. $P>0.005$.

The serum iron $(\mathrm{Fer}(\mu \mathrm{g} / \mathrm{dl})$ level is significantly decreased in Covi-19 than in control $(20.42 \pm 1.54 ; 85.15 \pm 5.90)$. Additionally, the serum levels of Ferriinemia, LDH and CRP were significantly higher in Covi-19an in Control .Ferriinémia(ng/ml) Control(72.35 \pm 12.02) Patients Covi-19 $(896.79 \pm 97.70) ; \mathrm{LDH}(\mathrm{u} / \mathrm{l})(184.3 \pm 9.72,366.32 \pm 33.94)$; $\mathrm{CRP}(\mathrm{mg} / \mathrm{l})(4.03 \pm 0.30,67.54 \pm 8.08)$.

\section{Discussion}

Covi-19 patients are usually exposed to potentially risk of mortality, maternal and neonatal consequences respiratory, renal problems and immunology disorder [7, 8]. The increase in Ferritinemia and decrease of Iron $(\mathrm{Fe})$ represent an imbalance for oxygenation of cells and the destiny of pyruvic acid which will be transformed to lactic acid via lacticodeshydrogénase (LDH), (effect Warburg).

\section{Conclusion}

Our results show the importance of these parameters to identify people a risk these are a simple and quick analyzes for Covi19. The indication to prevent infection is a supplementation on iron, trying to inhibit the enzyme LDH and to estimate ferriinemia. 


\section{References}

1. Coni P, Ronconi G, Carafa A (2020) Survival and success rate of spiral implants inserted mandible. Journal of Biological Regulators and Homeostaic Agents 34: 25-29.

2. Stephen A Lauer, Kyra H Grantz, Qifang Bi, Forrest K Jones, Qulu Zheng, et al. (2019) The Incubaion Period of Coronavirus Disease (COVID-19) From Publicly Reported Conirmed Cases: Esimaion and Applicaion. Annals of Internal Medicine 172: 577-582.

3. Tao Ai , Zhenlu Yang, Hongyan Hou (2019) Correlaion of Chest CT and RT-PCR Tesing in Coronavirus Disease (COVID-19) in China: A Report of 1014. Cases.

4. Hussin A, Rothan Siddappa N, Byrareddy (2020) The epidemiology and pathogenesis of coronavirus disease (COVID-19).

5. Lorenz F, Pawłowicz E, Klimkowska M, Soheir Beshara, Agnes Bulanda Brustad, et al. (2018) Ferriinemia and serum inlammatory cytokines in Swedish adults with Gaucher disease type 1. Blood Cells Mol Dis 68: 35-42.

6. Papillard-Marechal S, Sznajder M, Hurtado-Nedelec M, Yasmin Alibay, Caroline Martin-Schmitt, et al. (2012) Iron metabolism in paients with anorexia nervosa: elevated serum hepcidin concentraions in the absence of inlammaion. Am J Clin Nutr 95: 548-54

7. Coni P, Ronconi G, Carafa A, C Gallenga, R Ross, et al. (2020) Inducion of pro-inlammatory cytokines (IL-1 and IL-6) and lung inlammaion by Coronavirus-19 (COVI19 or SARS-CoV-2): ani-inlammatory strategies. J Biol Regul Homeost Agents 34: 1.

8. Caparros-Gonzalez RA (2020) Maternal and neonatal consequences of coronavirus COVID-19 infection during pregnancy: A Scoping Review. Rev Esp Salud Publica 94: e202004033.
Copyright: (C2020 Dr. Mustapha Haddouche.This is an open-access article distributed under the terms of the Creative Commons Attribution License, which permits unrestricted use, distribution, and reproduction in any medium, provided the original author and source are credited. 